\title{
"Functionally" univentricular hearts: impact of pre-natal diagnosis
}

\section{Antonio Francesco Corno*}

School of Medical Sciences, Universiti Sains Malaysia, Kubang Kerian, Malaysia

Edited by:

Bruno Marino, University Sapienza of

Rome, Italy

\section{Reviewed by:}

Yves Durandy, Centre Chirurgical

Marie Lannelongue, France

Federico Gutierrez-Larraya, Hospital

Universitario La Paz, Spain

*Correspondence:

Antonio Francesco Corno, East Midlands Congenital Heart Centre,

Glenfield Hospital, Leicester LE3 9QP, UK

e-mail: tonycorno2@gmail.com
Within the last few decades the pre-natal echocardiographic diagnosis of congenital heart defects has made substantial progresses, particularly for the identification of complex malformation. "Functionally" univentricular hearts categorize a huge variety of heart malformations. Since no one of the patients with these congenital heart defects can ever undergo a bi-ventricular type of repair, early recognition and decision-making from the neonatal period are required in order to allow for appropriate multiple-step diagnostic and treatment procedures, either of interventional cardiology and/or surgery, on the pathway of "univentricular" heart. In the literature strong disagreements exist about the potential impact of the pre-natal diagnosis on the early and late outcomes of complex congenital heart defects. This review of the recent reports has been undertaken to better understand the impact of pre-natal diagnosis in "functionally" univentricular hearts taking into consideration the following topics: pre-natal screening, outcomes and survival, general morbidity, neurologic and developmental consequences, pregnancy management and delivery planning, resources utilization and costs/benefits issues, ethical implications, parents counseling, and interruption of pregnancy versus treatment.

Keywords: hypoplastic left heart syndrome, peri-natal management, pre-natal diagnosis, surgical outcomes, univentricular heart

\section{INTRODUCTION}

Within the last few decades the pre-natal echocardiographic diagnosis of congenital heart defects has made substantial progresses, allowing the recognition of virtually almost all heart malformations between the 16th and 18th week of pregnancy, with a sensibility over $96 \%$ and a specificity close to $100 \%(1,2)$.

The potential impact of pre-natal diagnosis of congenital heart defects includes:

- knowledge of the natural history of the congenital heart defects "in utero,"

- potential pre-natal medical or interventional cardiology therapeutic interventions in the case of diagnosed heart failure, arrhythmias, or malformations with poor neonatal prognosis,

- safer management of the pregnancy itself,

- organization of the peri-natal period in or close to institutions with facilities available for the immediate management in the case of life-threatening heart malformations,

- parental counseling.

"Functionally" univentricular hearts categorize a huge variety of heart malformations, including but not limited to mitral atresia, tricuspid atresia, hypoplastic right or left heart, pulmonary atresia with intact ventricular septum and hypoplastic right ventricle, aortic atresia, double outlet right ventricle with hypoplastic right or left ventricle, complete atrio-ventricular septal defect with unbalanced ventricles, double inlet right or left ventricle.
Since no one of the patients with these congenital heart defects can ever undergo a bi-ventricular type of repair, early recognition and decision-making from the neonatal period are required in order to allow for appropriate multiple-step diagnostic and treatment procedures, either of interventional cardiology and/or surgery, on the pathway of "univentricular" heart.

In the literature strong disagreements exist about the potential impact of the pre-natal diagnosis on the early and late outcomes of complex congenital heart defects. This review of the recent reports has been undertaken to better understand the impact of pre-natal diagnosis in "functionally" univentricular hearts.

Of course it has to be taken into account the difficulty of having meaningful inferences from the literature, because of different inclusion criteria, relative small numbers of patients, different peri-operative managements, different end-points, and frequently insufficient statistical analysis.

\section{LITERATURE REVIEW}

The reported studies have been analyzed, taking into consideration the impact of the pre-natal diagnosis on the following topics:

- pre-natal screening,

- outcomes and survival,

- general morbidity,

- neurologic and developmental consequences,

- pregnancy management and delivery planning,

- resources utilization and costs/benefits issues,

- ethical implications, parents counseling, interruption of pregnancy versus treatment. 
Since any of the above topics presents direct implications with most of the other, the analysis has been performed trying to separately concentrate on each of the specific matters.

\section{PRE-NATAL SCREENING}

The pre-natal echographic screening is, by necessity, the first step in the process of pre-natal diagnosis and management of complex congenital heart defects, and therefore several reports are available in the literature, focused on the pre-natal screening, with considerations on general and specific issues (3-24).

\section{GENERAL NON-CARDIAC ISSUES}

A higher incidence of chromosomal disorders has always been found in fetuses with complex congenital heart defects $(4,8,16)$, as well as reduced fetal body weight and growth $(6,22)$, associated non-cardiac malformations (16), and the presence of situs inversus or heterotaxy (18).

\section{GENERAL CARDIAC ISSUES}

The incidence of complex congenital heart defects, including "functionally" univentricular hearts, has been observed as higher in the fetal pre-natal cardiac screening than in the post-natal diagnosis $(4,6,7,10,12,18,21,23)$.

The pre-natal cardiac screening can also been useful to detect fetal arrhythmias (12). Of course, the pre-natal diagnosis of complex congenital heart defect has opened the possibility of investigating potential fetal interventions (11).

\section{SPECIFIC CARDIAC ISSUES}

The most important information provided by the pre-natal echocardiographic screening is relative to the morphology, size, shape, and function of the ventricular chambers, even given the known difficulties in evaluating the ventricular performance based only on pre-natal echocardiography $(3,13,14,19,20)$.

Data on the morphology and functioning of the right atrioventricular valve are also relevant $(3,18,20)$.

In the specific cases of pre-natal diagnosis of hypoplastic left heart, the presence of restrictive inter-atrial communication, and the type and direction of the flow through the inter-atrial communication itself $(3,5,8,9,15)$, as well as the responsiveness of the fetal pulmonary vasculature to maternal hyperoxygenation (5), are indispensable for a prognostic evaluation and for the organization of the immediate post-natal treatment. Also the pre-natal evidence of endocardial fibroelastosis has clear negative prognostic implications $(20,24)$.

Useful information on the expected pathophysiology are the type and direction of flow through the patent ductus arteriosus (17), and particularly the presence of obstructed or retrograde flow through the aortic arch $(3,19)$.

A recent report proved the feasibility of pre-natal echocardiographic demonstration of the presence of ventriculo-coronary connections (24).

\section{SURVIVAL}

Survival is of course the most important parameter when evaluating the impact of the pre-natal diagnosis on the outcomes, and this issue has been addressed by many studies $(3,6,9,23,25-32)$.
While for a relatively simple congenital heart defect, such as aortic coarctation, the pre-natal diagnosis can contribute to improve the outcomes, including the survival (28), for a more complex defect, such as transposition of the great arteries, disagreement exists on the impact of the pre-natal diagnosis, going from reporting improved pre-operative as well as post-operative survival (25), to reporting only improved pre-operative condition but without any improvement of the post-operative outcomes (26).

When dealing with the most complex congenital heart defects, such as "functionally" univentricular hearts, because of the presence of multi-factorial elements influencing the outcomes, the discrepancy on the opinions about the impact of pre-natal diagnosis on survival becomes even more evident $(3,6,9,23,27$, 29-32).

In the past clinical studies failed to show an improved overall survival when the diagnosis of hypoplastic left heart syndrome was made pre-natal $(33,34)$.

In the more recent period, with substantially improved the perioperative care, a dichotomy clearly divided the reports demonstrating improved survival with pre-natal diagnosis $(3,9,30-32)$ from the studies showing similar survival between cases with pre-natal and post-natal diagnosis $(6,23,26,27,29)$.

Despite this discrepancy regarding the survival, almost all studies showed the improved pre-operative conditions obtained thanks to the pre-natal diagnosis and the subsequent timely transfer to tertiary referral hospital for intensive care treatment. General agreement exists on the observations that prompt referral after pre-natal diagnosis allows reducing the pre-operative metabolic acidosis and the subsequent need for bicarbonate administration, minimizing the needs for pre-operative inotropic support, reducing the incidence and degree of ventricular dysfunction and right atrio-ventricular valve regurgitation, and almost abolishing the occurrence of end-organs dysfunction $(3,6,26,27,29-32)$. The pre-natal diagnosis allows also early intervention in the case of identification of restrictive inter-atrial communication (9).

It is very interesting to note that, despite in the vast majority of the reported studies, the pre-operative conditions were significantly better in the cases with pre-natal diagnosis versus the post-natal diagnosis, this improvement failed to provide improved operative survival in about half of the clinical observations.

The impact of the pre-natal diagnosis has not yet been evaluated on the outcomes of the hybrid approach for hypoplastic left heart syndrome, with bilateral pulmonary artery banding and stenting of the patent ductus arteriosus. This treatment option is increasingly considered or used in the recent years in the patients considered with high-risk for the conventional surgical management (35-43).

\section{GENERAL MORBIDITY}

The comparison between the two groups with pre-natal and post-natal diagnosis with regard to the post-operative morbidity showed discrepancies exactly as for the survival $(3,6,26,29,31)$.

Few studies showed reduced post-operative morbidity in the group with pre-natal diagnosis $(3,6,31)$. The reasons to support the decreased morbidity were the better pre-operative conditions, particularly because of the reduced metabolic acidosis ( 3 , 31 ), reduced duration of mechanical ventilation (6), and reduced 
need for emergency operation (6), and the observations of better post-operative ventricular function $(3,31)$.

Other researchers failed to observe reduced morbidity in the group of patients with pre-natal diagnosis $(26,29)$.

\section{NEUROLOGIC AND DEVELOPMENTAL CONSEOUENCES}

Among the studies investigating the early and late neurocognitive development in children with complex congenital heart defects, very few had taken into consideration the impact of pre-natal diagnosis $(27,30,44,45)$.

In fetuses with hypoplastic left heart syndrome, a significant decrease in head growth and chronic diffuse white matter injury of variable severity have been reported (44). The pre-natal diagnosis has been associated with reduced incidence of adverse perioperative neurologic events (27), as well as reduce incidence, and lesser severity of neurocognitive deficits (45).

Despite it is well known that children with complex congenital heart defects present an increased prevalence of central nervous system abnormalities, due to inadequate development, pre-natal ischemia, post-natal cyanosis, and exposure to cardio-pulmonary bypass, it seems that pre-natal diagnosis, allowing the reduction of the peri-operative multi-organ injuries, can also improve the long-term beuroligic outcome $(27,30,45)$.

\section{PREGNANCY MANAGEMENT AND DELIVERY PLANNING}

Quite evident is the agreement on the positive impact of prenatal diagnosis of complex congenital heart defect, particularly "functionally" univentricular heart, in the management of the pregnancy and the appropriate planning of the delivery $(3,7,17,46-49)$.

After pre-natal echocardiographic diagnosis of "functionally" univentricular heart, a maternal-fetal care program can be established, with the pregnancy follow-up and the mode of elective delivery, either cesarean or vaginal with induced or spontaneous labor, timely planned and organized in a tertiary referral hospital. This allows appropriate multi-disciplinary management of the neonate from the delivery room to the operating room, including echocardiographic confirmation of the cardiac diagnosis shortly after birth, and immediate transfer to the neonatal intensive care unit for prompt administration of prostaglandins, maintenance of normal acid-base status, and tracheal intubation with mechanical ventilation to provide and maintain adequate balance between the systemic and the pulmonary circulation $(3,17,46-49)$.

\section{RESOURCES UTILIZATION AND COSTS/BENEFITS ISSUES}

In an era of money-driven medicine, the efforts toward cost containing have reached also the potential impact of pre-natal diagnosis of complex congenital heart defects, including "functionally" univentricular hearts $(50,51)$.

The costs of training ultrasound technicians and make them capable to perform pre-natal diagnosis of complex congenital heart defects have been compared with the costs of organizing the emergency transports of neonates with post-natal diagnosis to specialized care centers. The results showed a substantial saving, considering the costs of training the ultrasound technicians plus the organization of elective transfer for delivery to a tertiary referral center in the case of pre-natal diagnosis of complex congenital heart defect versus emergency transportation and care after postnatal diagnosis of similar heart malformations (50). The saving was directly correlated with the detection rate, with considerable increase for each day of exposure of the ultrasound technicians to the specific training (50).

\section{ETHICAL IMPLICATIONS, PARENTS COUNSELING, INTERRUPTION OF PREGNANCY VERSUS TREATMENT}

All these points, strictly correlated, are not quantifiable in scientific or mathematic terms, such as the sensitivity of the pre-natal screening or the percentage of survival. A very large number of studies have tried to cover the matter, taking in consideration all the various aspects, and the unavoidable inter-relationships $(3,8,16,52-74)$.

First of all, in this review all cases with the pre-natal diagnosis of "functionally" univentricular heart have been taken into consideration. In this regard, despite decent medium and long-term results obtained from few decades with the univentricular type of repair (75-79), the concept of "intractable" congenital heart defect is still associated with the diagnosis of univentricular heart, because of the hazardous long-term results $(57,69)$. "Intractable" (57) or "uncorrectable" (69) has been defined the heart malformations not suitable to bi-ventricular repair, and therefore where the only option available for treatment remains multi-staged complex palliation programs toward univentricular type of repair or heart transplant. The only alternative possible in these cases is abstention from any treatment or compassionate care $(57,69)$.

With regard to the option of heart transplant, evident discrepancies exist between the reported data in relationship with the timing of the heart transplant, if the option was utilized as first stage, after failed first stage Norwood type of procedure, after the second stage (bidirectional Glenn anastomosis), or after failed Fontan circulation (80-83).

In fact it has been reported $(3,8,16,53,59,60,64,66,67,69,70$, 73 ) that following the pre-natal diagnosis of complex congenital heart defect not suitable for bi-ventricular repair, the decision to terminate the pregnancy or for compassionate care has been taken with percentages varying from $8(64)$ through $16(8,16), 30(59$, 60 ), 33 (3), up to $47 \%$ (73).

The decision for abstention from treatment, very difficult for all couples of parents, was generally justified by one or more of the following reasons: to avoid a described poor hospital survival and diminished quality of life, to prevent the child from suffering $(53,59)$, to reduce the stress to the parents themselves and to the siblings $(53,69)$, and because of the presence of chromosomes disorders or major extra-cardiac malformations (73).

In almost all cases the decision of the parents has been influenced by availability of pre-natal diagnosis of complex congenital heart defect $(16,53,59,70,73)$. Because of the striking importance of the impact of pre-natal diagnosis on the decisionmaking process, general agreement exists that following pre-natal diagnosis of complex congenital heart defect the parents should be offered a comprehensive multi-disciplinary pre-natal evaluation, including karyotyping, detailed intra-cardiac and extracardiac assessment, in order to obtain the most possible accurate prognosis for early and long term outcomes $(8,16,52$, $59-62,64,66,69,74)$. It is vital to give the parents and their 
families all information and support to prepare their heart and mind (69).

It is easy to agree about the importance of a multi-disciplinary team to assist the families after pre-natal diagnosis of complex congenital heart defect. Much more difficult is to define the "who, what, when, where and how" relative to the communication of the information to the parents.

The information of pre-natal diagnosis of complex congenital heart defect is unavoidably followed by a major psychological crisis of the parents and their family: the state of shock, the short time available to make decisions, the frequently contradictory information available about early and long-term outcomes, limit to the parents the possibility for autonomous choices (53). Furthermore, autonomous decisions may be neither possible nor desirable for all the parents (53).

The parents' counseling, already difficult because of the problem of communications between caregivers and families, can be further complicated by the influence of religion, culture, individual cognitive, emotional, and social processes $(54,55,69,71)$. As a matter of fact, cross-cultural patient care is an issue challenging the healthcare providers: caring for patients who reject some biomedical treatments because of religious or cultural reasons requires knowledge of that person's beliefs to establish an effective treatment $(55,71)$.

Another well-known difficulty of the parental counseling is due to the fact that nowadays the parents have easy access, through internet, to the best results reported by the best hospitals, while the same results are most probably not obtained in the local hospital. At this point it is very uneasy for a doctor to confess that the results of the local hospital are less satisfactory that the gold standard reported on the net.

During the process of parents' counseling, when considering the information received or perceived by the parents on the potential or expected outcomes, well known is the influence or the type and quality of messages received from the caregivers. While it is quite intuitive that the influence by optimistic physicians at surgical departments seemed important for a choice orientated toward surgery, less expected is the observation that the opinions offered by the professionals have offended some parents $(61,62,67-69,74)$.

The importance of doctors' belief, varying from the two extremes, optimism regarding the potential long-term outcomes, or serious suggestion to consider the option of termination of pregnancy, has determinant implications on the parental perceptions and their subsequent decision-making process $(56,65,67,70,72)$.

Also the opinion of the patients, and their families, should be taken into consideration, because there are certainly different degree of acceptance of a limited quality of life by different individuals and families.

Doctor's recommendations for treatment are consistent with selecting the option that maximizes the chance of the best outcome, without necessarily minimizing the chance of the worst outcome; even their beliefs about likely outcomes vary according to the patient group they encountered (56).

The risk communication is particularly problematic when the evidence base is limited or when there are several options with
Table 1 | Results of the "Audience Response Survey".

\begin{tabular}{lcc}
\hline Options & Patient (\%) & Family member (\%) \\
\hline Norwood & 73 & 26 \\
Heart transplant & 0 & 1 \\
Compassionate care & 6 & 5 \\
Pregnancy interruption & 21 & 68 \\
\hline
\end{tabular}

many possible outcomes (56). Finally, because of the complexity of the pre-natal diagnosis and the subsequent huge variety among the potential long-term outcomes, very difficult is for the caregivers is to maintain a professional attitude, not influenced by the personal feelings and opinions.

Not easy is to find an answer to the question: "What if it were your child?" (58). An attempt to answer the above question has been made with an "Audience Response Survey" at the first joint meeting of the "Congenital Heart Surgeons Society" (of North America) and the European Association Congenital Heart Surgeons, collecting the answer form 73 experienced congenital heart surgeons (63). The results of the survey are represented in Table 1. Evident is the striking difference between the suggestion given by the surveyed heart surgeons if the pre-natal diagnosis was done for a patient rather than for a family member.

\section{CONCLUSION}

The impact of pre-natal diagnosis of complex congenital heart defects where the only treatment option is a univentricular heart type of repair has dramatic implications for the parents, their families, and all the involved caregivers.

The huge incidence of variable morphologic characteristics and subsequent pathophysiologic patterns, the potential association of chromosomal disorders, associated intra-cardiac and extracardiac malformation, and the several clinical reports with evolving short- and long-term outcomes make the parents counseling and the subsequent decision-making process extremely difficult.

Better information, and therefore suggestions, could come from prospective data collection of the outcomes obtained with the currently available peri-operative techniques.

\section{REFERENCES}

1. Allan LD, Crawford DC, Chita SK, Tynan MJ. Prenatal screening for congenital heart disease. Br Med J (1986) 292:1717-21. doi:10.1136/bmj.292.6537.1717

2. Bull C. Current and potential impact of fetal diagnosis on prevalence and spectrum of serious congenital heart disease at term in the UK. British paediatric cardiac association. Lancet (1999) 354:1242-7.

3. Tworetzy W, McElhinney DB, Reddy VM, Brook MM, Hanley FL, Silverman NH. Improved surgical outcome after fetal diagnosis of hypoplastic left heart syndrome. Circulation (2001) 103:1269-73. doi:10.1161/01.CIR.103.9.1269

4. McBrien A, Sands A, Craig B, Doman J, Casey F. Major congenital heart disease: antenatal detection, patient characteristics and outcomes. J Matern Fetal Neonatal Med (2009) 22:101-5. doi:10.1080/14767050802483106

5. Szwast A, Tian Z, McCann M, Donaghue DD, Rychik J. Vasoreactive response to maternal hyperoxygenation in the fetus with hypoplastic left hart syndrome. Circ Cardiovasc Imaging (2010) 3:172-8. doi:10.1161/CIRCIMAGING.109.848432

6. Levey A, Glickstein JS, Kleinman CS, Levasseur SM, Chen J, Gersony WM, et al. The impact of prenatal diagnosis of complex congenital heart disease on neonatal outcomes. Pediatr Cardiol (2010) 31:587-97. doi:10.1007/s00246-0109648-2

7. McBrien A, Sands A, Craig B, Doman J, Casey F. Impact of a regional training program in fetal echocardiography for sonographers on the antenatal detection 
of major congenital heart disease. Ultrasound Obstet Gynecol (2010) 36:279-84. doi:10.1002/uog.7616

8. Rychik J, Szwast A, Natarajan S, Quartermain M, Donaghue DD, Combs J, et al. Perinatal and early surgical outcome for the fetus with hypoplastic left heart syndrome; a 5-year single institutional experience. Ultrasound Obstet Gynecol (2010) 36:465-70. doi:10.1002/uog.7674

9. Szwast A, Rychik J. The use of reconstructive surgery to improve quality of life and survival in prenatal hypoplastic left heart syndrome. Future Cardiol (2012) 8:215-25. doi:10.2217/fca.12.2

10. Trivedi N, Levy D, Tarsa M, Anton T, Hartney C, Wolfson T, et al. Congenital cardiac anomalies: prenatal readings versus neonatal outcomes. J Ultrasound Med (2012) 31:389-99.

11. Van Aerschot I, Rosenblatt J, Boudjemline Y. Fetal cardiac interventons: myths and facts. Arch Cardiovasc Dis (2012) 105:366-72. doi:10.1016/j.acvd. 2012.01.011

12. Emam SM. High prevalence of complex congenital cardiac anomalies detected by fetal echocardiography in a cohort of Saudi women referred for prenatal assessment. J Egypt Soc Parasitol (2012) 42:281-90. doi:10.12816/0006317

13. Brooks PA, Khoo NS, Mackie AS, Homberger LK. Right ventricular function in fetal hypoplastic left heart syndrome. J Am Soc Echocardiogr (2012) 25:1068-74. doi:10.1016/j.echo.2012.06.005

14. McCandless RT, Puchalski MD, Minich LL, Menon SC. Prenatally diagnosed coarctation: a more sinister disease? Pediatr Cardiol (2012) 33:1160-4. doi:10. 1007/s00246-012-0275-y

15. Enzensberger C, Vogel M, Degenhardt J, Fass N, Kawecki A, Kohl T, et al. Fetal pulmonary venous flow and restrictive foramen ovale in hypoplastic left heart. Ultraschall Med (2012) 33:E38-45. doi:10.1055/s-0032-1325376

16. Axt-Fliedner R, Enzensberger C, FAss N, Vogel M, Kawecki A, Weichert J, et al. Fetal diagnosis of hypoplastic left heart, associations and outcomes in the current era. Ultraschall Med (2012) 33:E51-6. doi:10.1055/s-0032-1312830

17. Quartermain MD, Glatz AC, Goldberg DJ, Cohen MS, Elias MD, Tian Z, et al. Pulmonary outflow tract obstruction in fetuses with complex congenital heart disease: predicting the need for neonatal intervention. Ultrasound Obstet Gynecol (2013) 41:47-53. doi:10.1002/uog.11196

18. Beaton AZ, Pike JI, Stallings C, Donofrio MI. Predictors of repair and outcome in prenatally diagnosed atrioventricular septal defects. J Am Soc Echocardiogr (2013) 26:208-16. doi:10.1016/j.echo.2012.11.007

19. Weber RW, Ayala-Arnez R, Atiyah M, Etoom Y, Manlhiot C, McCrindle BW, et al. Foetal echocardiographic assessment of borderline small left ventricles can predict the need for postnatal intervention. Cardiol Young (2013) 23:99-107. doi:10.1017/S1047951112000467

20. Natarian S, Szwast A, Tian Z, McCann M, Soffer D, Rychik J. Right ventricular mechanism in the fetus with hypoplastic left heart syndrome. J Am Soc Echocardiogr (2013) 26:515-20. doi:10.1016/j.echo.2013.02.001

21. Asplin N, Dellgren A, Conner P. Education in obstetrical ultrasound; an important factor for increasing the prenatal detection of congenital heart disease. Acta Obstet Gynecol Scand (2013) 92:804-8. doi:10.1111/aogs.12140

22. Cnota JF, Hangge PT, Wang Y, Woo JG, Hinton AC, Divanovic AA, et al. Somatic growth trajectory in the fetus with hypoplastic left heart syndrome. Pediatr Res (2013) 74:284-9. doi:10.1038/pr.2013.100

23. Oster ME, Kim CH, Kusano AS, Cragan JD, Dressler P, Hales AR, et al. A population-based study of the association of prenatal diagnosis with survival rate for infants with congenital heart defects. Am J Cardiol (2014) 113:1036-40. doi:10.1016/j.amjcard.2013.11.066

24. Axt-Fuedner R, Tenzer A, Kawecki A, Degenhardt J, Schranz D, Valeske K, et al. Prenatal assessment of ventriculocoronary connections and ventricular endocardial fibroelastosis in hypoplastic left heart. Ultrashall Med (2014) 35:357-63. doi:10.1055/s-0034-1366361

25. Bonnet D, Coltri A, Butera G, Fermont L, Le Bidois J, Kachaner J, et al. Detection of transposition of the great arteries in fetuses reduces neonatal morbidity and mortality. Circulation (1999) 99:916-8. doi:10.1161/01.CIR.99.7.916

26. Kumar RK, Newburger JW, Gauvreau K, Kamenir SA, Hornberger LK. Comparison of outcome when hypoplastic left heart syndrome and transposition of the great arteries are diagnosed prenatally versus when diagnosis of these two conditions is made only postnatally. Am J Cardiol (1999) 83:1649-53. doi:10.1016/S0002-9149(99)00172-1
27. Mahle WT, Clancy RR, McGaurn SP, Goin JE, Clark BJ. Impact of prenatal diagnosis on survival and early neurologic morbidity in neonates with the hypoplastic left heart syndrome. Pediatrics (2001) 107:1277-82. doi:10.1542/peds.107.6. 1277

28. Franklin O, Burch M, Manning N, Sleeman K, Gould S, Archer N. Prenatal diagnosis of coarctation of the aorta improves survival and reduces morbidity. Heart (2002) 87:67-9. doi:10.1136/heart.87.1.67

29. Kipps AK, Feuille C, Azakie A, Hoffman JI, Tabbutt S, Brook MM, et al. Prenatal diagnosis of hypoplastic left heart syndrome in current era. Am J Cardiol (2011) 108:421-7. doi:10.1016/j.amjcard.2011.03.065

30. Feinstein JA, Benson DW, Dubin AM, Cohen MS, Maxey DM, Mahle WT, et al. Hypoplastic left heart syndrome: current considerations and expectations. J Am Coll Cardiol (2012) 59:S1-42. doi:10.1016/j.jacc.2011.09.022

31. Markkanen HK, Pihkala JI, Salminen JT, Saarinen MM, Hornberger LK, Ojala TH. Prenatal diagnosis improves the postnatal cardiac function in a populationbased cohort of infants with hypoplastic left heart syndrome. J Am Soc Echocar$\operatorname{diogr}(2013)$ 26:1073-9. doi:10.1016/j.echo.2013.05.005

32. Szwast A, Rychik J. Prenatal diagnosis of hypoplastic left heart syndrome: can we optimize outcomes? J Am Soc Echocardiogr (2013) 26:1080-3. doi:10.1016/j. echo.2013.07.001

33. Kern JH, Hayes CJ, Michler RE, Gersony WM, Quaegebeur JM. Survival and risk factor analysis for the Norwood procedure for hypoplastic left heart syndrome. Am J Cardiol (1997) 80:170-4. doi:10.1016/S0002-9149(97)00313-5

34. Allan LD, Apfel HD, Printz BF. Outcome after prenatal diagnosis of the hypoplastic left hart syndrome. Heart (1998) 79:371-3. doi:10.1136/hrt.79.4.371

35. Bacha EA. Individualized approach in the management of patients with hypoplastic left heart syndrome (HLHS). Semin Thorac Cardiovasc Surg Pediatr Card Surg Annu (2013) 16:3-6. doi:10.1053/j.pcsu.2013.01.001

36. Galantowicz M. In favor of the hybrid stage 1 as the initial palliation for hypoplastic left heart syndrome. Semin Thorac Cardiovasc Surg Pediatr Card Surg Annu (2013) 16:62-4. doi:10.1053/j.pcsu.2013.01.005

37. Chetan D, Kotani Y, Jacques F, Poynter JA, Lee KJ, Chaturvedi RR, et al. Surgical palliation strategy does not effect interstage ventricular dysfunction or atrioventricular valve regurgitation in children with hypoplastic left heart syndrome and variants. Circulation (2013) 128:S205-12. doi:10.1161/CIRCULATIONAHA. 112.000380

38. Chauhan M, Mastropietro VW. Hypoplastic left heart syndrome in the emergency department: an update. J Emerg Med (2014) 46:e51-4. doi:10.1016/j. jemermed.2013.08.061

39. Schranz D. Hybrid approach in hypoplastic left heart syndrome. Heart (2014) 100:750-1. doi:10.1136/heartjnl-2013-305404

40. Lloyd DF, Cutler L, Tibby SM, Vimalesvaran S, Qureshi SA, Rosenthal E, et al. Analysis of preoperative condition and interstage mortality in Norwood and hybrid procedures for hypoplastic left heart syndrome using the Aristotle scoring system. Heart (2014) 100:775-80. doi:10.1136/heartjnl-2013-304759

41. Brescia AA, Jureidini S, Danon S, Armbrecht E, Fiore AC, Huddleston CB. Hybrid versus Norwood procedure for hypoplastic left heart syndrome: contemporary series from a single center. J Thorac Cardiovasc Surg (2014) 147:1777-82. doi:10.1016/j.jtcvs.2014.02.066

42. Harada Y. Current status of the hybrid approach for the treatment of hypoplastic left heart syndrome. Gen Thorac Cardiovasc Surg (2014) 62:334-41. doi:10. 1007/s11748-013-0347-9

43. Dave H, Rosser B, Knirsch W, Hubler M, Pretre R, Kretschmar O. Hybrid approach for hypoplastic left heart syndrome and its variants: the fate of the pulmonary arteries. Eur J Cardiothorac Surg (2014) 46:14-9. doi:10.1093/ejcts/ ezt604

44. Hinton RB, Andelfinger G, Sekar P, Hinton AC, Gendron RL, Michelfelder EC, et al. Prenatal head growth and white matter injury in hypoplastic left heart syndrome. Pediatr Res (2008) 64:364-9. doi:10.1203/PDR.0b013e3181827bf4

45. Calderon J, Angeard N, Moutier S, Plumet MH, Jambaqué I, Bonnet D. Impact of prenatal diagnosis on neurocognitive outcomes in children with transposition of the great arteries. J Pediatr (2012) 161:94-8. doi:10.1016/j.jpeds.2011.12.036

46. Peterson AL, Quartermain MD, Ades A, Khalek N, Johnson MP, Rychik J. Impact of mode of delivery on markers of perinatal hemodynamics in infants with hypoplastic left heart syndrome. J Pediatr (2011) 159:64-9. doi:10.1016/j.jpeds. 2011.01.004 
47. Colby CE, Carey WA, Blumenfeld YJ, Hintz SR. Infants with prenatally diagnosed anomalies: special approaches to preparation and resuscitation. Clin Perinatol (2012) 39:871-87. doi:10.1016/j.clp.2012.09.012

48. Trento LU, Pruetz JD, Chang RK, Detterich J, Sklansky MS. Prenatal diagnosis of congenital heart disease: impact of mode of delivery on neonatal outcome. Prenat Diagn (2012) 32:1250-5. doi:10.1002/pd.3991

49. Morris SA, Ethen MK, Penny DJ, Canfield MA, Minard CG, Fixler DE, et al. Prenatal diagnosis, birth location, surgical center, and neonatal mortality in infants with hypoplastic left heart syndrome. Circulation (2014) 129:285-92. doi:10.1161/CIRCULATIONAHA.113.003711

50. Jegatheeswaran A, Oliveira C, Batsos C, Moon-Grady AJ, Silverman NH, Hornberger LK, et al. Costs of prenatal detection of congenital heart disease. Am J Cardiol (2011) 108:1808-14. doi:10.1016/j.amjcard.2011.07.052

51. Donofrio MT, Levy RJ, Schuette JJ, Skurow-Todd K, Sten MB, Stallings C, et al. Specialized delivery room planning for fetuses with critical congenital heart disease. Am J Cardiol (2013) 111:737-47. doi:10.1016/j.amjcard.2012.11.029

52. Kawataki M. Ethical issues and decision-making in fetal cardiology. Pediatr Int (1999) 41:733-6. doi:10.1046/j.1442-200x.1999.01156.x

53. Vandvik IH, Forde R. Ethical issues in parental decision-making. An interview study of mothers of children with hypoplastic left heart syndrome. Acta Pediatr (2000) 89:1129-33. doi:10.1111/j.1651-2227.2000.tb03363.x

54. Barnes LL, Plotnikoff GA, Fox K, Pendleton S. Spirituality, religion, and pediatrics: intersecting worlds of healing. Pediatrics (2000) 106:899-908.

55. Barnes LL, Plotnikoff GA. Fadiman and beyond: the dangers of extrapolation. Bioethics Forum (2001) 17:32-40.

56. Rakow T. Differences in belief about likely outcomes account for the differences in doctors' treatment preferences: but what accounts for the differences in belief? Qual Health Care (2001) 10:S44-9. doi:10.1136/qhc.0100044

57. Kachaner J. Intractable neonatal heart disease: a controversy. Arch Pediatr (2002) 9:S49-54. doi:10.1016/S0929-693X(01)00777-1

58. Gutgesell HP. What if it were your child? Am J Cardiol (2002) 89:856. doi:10.1016/S0002-9149(02)02199-9

59. Menahem S, Grimwade J. Pregnancy termination following prenatal diagnosis of serious heart disease in the fetus. Early Hum Dev (2003) 73:71-8. doi:10.1016/S0378-3782(03)00078-1

60. Menahem S, Grimwade J. Counselling strategies in the prenatal diagnosis of major heart abnormality. Heart Lung Circ (2004) 13:261-5. doi:10.1016/j.hlc. 2004.06.009

61. Rempel GR, Cender LM, Lynam MJ, Sandor GG, Farquharson D. Parents' perspectives on decision making after diagnosis of congenital heart disease. J Obstet Gynecol Neonatal Nurs (2004) 33:64-70. doi:10.1177/0884217503261092

62. Menahem S, Grimwade J. Pre-natal counseling: helping couples make decisions following the diagnosis of severe heart disease. Early Hum Dev (2005) 81:601-7. doi:10.1016/j.earlhumdev.2005.02.001

63. Jacobs JP, Ungerleider RM, Tchervenkov CI, Ebels T, Laliberté E, Maruszewski $\mathrm{B}$, et al. Opinions from the audience response survey at the first joint meeting of the congenital heart surgeons' society and the European congenital heart surgeons association. Semin Thorac Cardiovasc Surg Pediatr Card Surg Annu (2005) 198:217.

64. Yeu BK, Chalmers R, Shekleton P, Grimade J, Menahem S. Fetal cardiac diagnosis and its influence on the influence on the pregnancy and newborn: a tertiary centre experience. Fetal Diagn Ther (2008) 24:241-5. doi:10.1159/000151669

65. Prsa M, Holly CD, Carnevale FA, Justino H, Rohlicek CV. Attitudes and practices of cardiologists and surgeons who manage HLHS. Pediatrics (2010) 125:e625-30. doi:10.1542/peds.2009-1678

66. Mavroudis C, Mavroudis CD, Farrell RM, Jacobs JP, Kodish ED. Informed consent, bioethical equipoise, and hypoplastic left heart syndrome. Cardiol Young (2011) 21(Suppl-2):133-40. doi:10.1017/S1047951111001715

67. Murtuza B, Elliott MJ. Changing attitudes to the management of hypoplastic left heart syndrome: a European perspective. Cardiol Young (2011) 21(Suppl2):148-58. doi:10.1017/S1047951111001739

68. Menahem S. Ethical questions arising from counseling in fetal complex congenital heart disease. Monash Bioeth Rev (2012) 30:62-7. doi:10.1007/BF03351340

69. McKechnie AC, Pridham K. Preparing heart and mind following prenatal diagnosis of complex congenital heart defect. Qual Health Res (2012) 22:1694-706. doi:10.1177/1049732312458371
70. Hilton-Kamm D, Chang RK, Sklansky M. Prenatal diagnosis of hypoplastic left heart syndrome: impact of counseling patterns on parental perceptions and decisions regarding termination of pregnancy. Pediatr Cardiol (2012) 33:1402-10. doi:10.1007/s00246-012-0366-9

71. Dean PN, McHugh KE, Conaway MR, Hillman DG, Gutgesell HP. Effects of race, ethnicity, and gender on surgical mortality in hypoplastic left heart syndrome. Pediatr Cardiol (2013) 34:1829-36. doi:10.1007/s00246-013-0723-3

72. Caldera K, Ha D, Menahem S. The development of a CD-ROM: an aid to fetal cardiac diagnosis and counseling. Fetal Diagn Ther (2013) 33:61-4. doi:10.1159/000339655

73. Nell S, Wijngaarde CA, Pistorius LR, Slieker M, ter Heide H, Manten GT, et al. Fetal heart disease: severity, associated anomalies and parental decision. Fetal Diagn Ther (2013) 33:235-40. doi:10.1159/000346564

74. Bevilacqua F, Palatta S, Mirante N, Cuttini M, Seganti G, Dotta A, et al. Birth of a child with congenital heart disease: emotional reactions of mothers and fathers according to time of diagnosis. J Matern Fetal Neonatal Med (2013) 26:1249-53. doi:10.3109/14767058.2013.776536

75. Corno AF, Becker AE, Bulterijs AHK, Lam J, Nijveld A, Schuller JL, et al. Univentricular heart: can we alter the natural history? Ann Thorac Surg (1982) 34:716-26. doi:10.1016/S0003-4975(10)60917-4

76. Corno AF. Surgery for congenital heart disease. Curr Opin Cardiol (2000) 15:238-43. doi:10.1097/00001573-200007000-00005

77. Atz AM, Travison TG, McCrindle BW, Mahony L, Glatz AC, Kaza AK, et al. Cardiac performance and quality of life in patients who have undergone the Fontan procedure with and without prior superior cavopulmonary connection. Cardiol Young (2013) 23:335-43. doi:10.1017/S1047951112001175

78. d'Udekem Y, Iyengar AJ, Galati JC, Forsdick V, Weintraub RG, Wheaton GR, et al. Redefining expectations of long-term survival after the Fontan procedure: twenty-five years of follow-up from the entire population of Australia and New Zealand. Circulation (2014) 130(Suppl 1):S32-8. doi:10.1161/ CIRCULATIONAHA.113.007764

79. Arnold RR, Loukanov T, Gorenflo M. Hypoplastic left heart syndrome: unresolved issues. Front Pediatr (2014) 2:125. doi:10.3389/fped.2014.00125

80. Rossano JW, Shaddy RE. Heart transplant after the Fontan operation. Cardiol Young (2013) 23:841-6. doi:10.1017/S1047951113001662

81. Iyengar AJ, Sharma VJ, Weintraub RG, Shipp A, Brizard CP, d'Udekem Y, et al. Surgical strategies to facilitate heart transplantation in children after failed univentricular palliations: the role of advanced intraoperative surgical preparation. Eur J Cardiothorac Surg (2014) 46:480-5. doi:10.1093/ejcts/ ezu004

82. De Rita F, Hasan A, Haynes S, Crossland D, Kirk R, Ferguson L, et al. Mechanical cardiac support in children with congenital heart disease with intention to bridge to heart transplantation. Eur J Cardiothorac Surg (2014) 4:656-62. doi:10.1093/ejcts/ezu039

83. Alsoufi B, Slesnick T, McCracken C, Ehrlich A, Kanter K, Schlosser B, et al. Current outcomes of the Norwood operation in patients with single-ventricle malformations other than hypoplastic left heart syndrome. World J Pediatr Congenit Heart Surg (2015) 6:46-52. doi:10.1177/2150135114558069

Conflict of Interest Statement: The author declares that the research was conducted in the absence of any commercial or financial relationships that could be construed as a potential conflict of interest.

Received: 12 December 2014; accepted: 16 February 2015; published online: 27 February 2015.

Citation: Corno AF (2015) "Functionally" univentricular hearts: impact of pre-natal diagnosis. Front. Pediatr. 3:15. doi: 10.3389/fped.2015.00015

This article was submitted to Pediatric Cardiology, a section of the journal Frontiers in Pediatrics.

Copyright (c) 2015 Corno. This is an open-access article distributed under the terms of the Creative Commons Attribution License (CC BY). The use, distribution or reproduction in other forums is permitted, provided the original author(s) or licensor are credited and that the original publication in this journal is cited, in accordance with accepted academic practice. No use, distribution or reproduction is permitted which does not comply with these terms. 